\title{
The Study of China Outward Foreign Direct Investment's Location Choice
}

\author{
Zhenli Wang* \\ School of Development Studies \\ Yunnan University \\ Kunming, China \\ 309616077@qq.com
}

\author{
Ying $\mathrm{Hu}$ \\ School of Economics \\ Yunnan University \\ Kunming, China \\ huyingchine@qq.com
}

\begin{abstract}
To pave the road of pushing China OFDI forward in the right direction, targeted experiments have been in full blossom. Through choosing 70 main recipient countries aging from 2003 to 2014 as research subjects when Chinese overseas investment expanded faster and faster, and establishing multiple panel data models to analyze, some conclusions were drawn: China tend to choose states with certain characteristics, which are good momentum of economic development, deeper level of trade exchange, imperfect infrastructure of transportation and communication, and serious solidification of political corruption, however cultural practices, tax burden, comprehensive competitiveness and other factors only in certain circumstances exhibited significant. What's more, combined with international business cases, these empirical results are consistent with realities.
\end{abstract}

Keywords-Foreign Direct Investment; Location Choice; Index System

\section{INTRODUCTION}

To ensure better coordination in pursuing the "bring in" and "go global" strategies, China has been making full use of the gradually accumulated human capital and physical capital to dig out available resources with distinct geographical features and modern trends since 1978. Whether the location choice is proper and correct determines the pulse of the Chinese enterprises' OFDI.

In the late 20th century, the theory of Chinese OFDI location choice was always based on the gravity model, Chinese OFDI was inversely proportional to distance between the host country and China [1-3], Chinese OFDI and host country GDP were directly related[1-2;4-5], which was consistent with the basic conclusions of gravity model. In the 1990's, relying on geographical and cultural advantages, Chinese OFDI occurred in the neighboring countries, whose style was state-led, small-scale, and market-oriented, with the purpose of reducing the trade barriers for enterprises to expand overseas market.

Early in the 21th century, with the deepening of China's reform and opening up, the total industrial output value was growing substantially, whereas the overall level of technology just improved by a small margin, Yang and Zhang thought although China was low level of economic development at the time, the main driving force supporting OFDI existed in two aspects[6]. Firstly, vast land and rich natural resources gave China an opportunity to exploit the advantages in resource endowment; Secondly, Chinese government made strong tilt policies to assist some strategic industries by preferential loans and tax relief. Because of rapid increase in national wealth, China gradually seized the initiative of OFDI, and the study of exploring OFDI influence factors, began to focus on some others aspects in host economy, such as tax burden, political system, cultural similarity and so on.

In general, Chinese OFDI had a negative correlation with the extent of the tax burden, since high tax environment seriously added to business cost. With the method of building the factory in some duty-free or low-level tax cost regions, these so-called "overseas enterprises" had the great privilege of implementing profitable activities when they came back to China market again. Additionally, there was a substitute relationship between tax factors and institutional factors to some extent [3;7]. Significant correlation existed between Chinese OFDI and the establishment of host company system, considering that strict orders can lower the transaction cost of enterprises. On the contrary, inverse correlation lay in legal \& political construction, according that rent-seeking activities can clear the barriers to entry[3;8-9]. Under the influence of Chinese ancient cultural heritage and propagation, the higher the degree of culture similarity was, the better economic intercourses and cultural exchanges would be, so China OFDI had opposite relevance to cultural distance $[8 ; 10]$.

Although single indicator has been focused on and detailed analyses, comprehensive analyses involving the macroinfluential factors above mentioned are left in the basket, especially when different factors intervene mutually.

On the basis of previous studies combined with researching of existing conditions, a theoretical framework is summarized and further developed to investigate systematically the diversification question.

\footnotetext{
* Corresponding author
} 


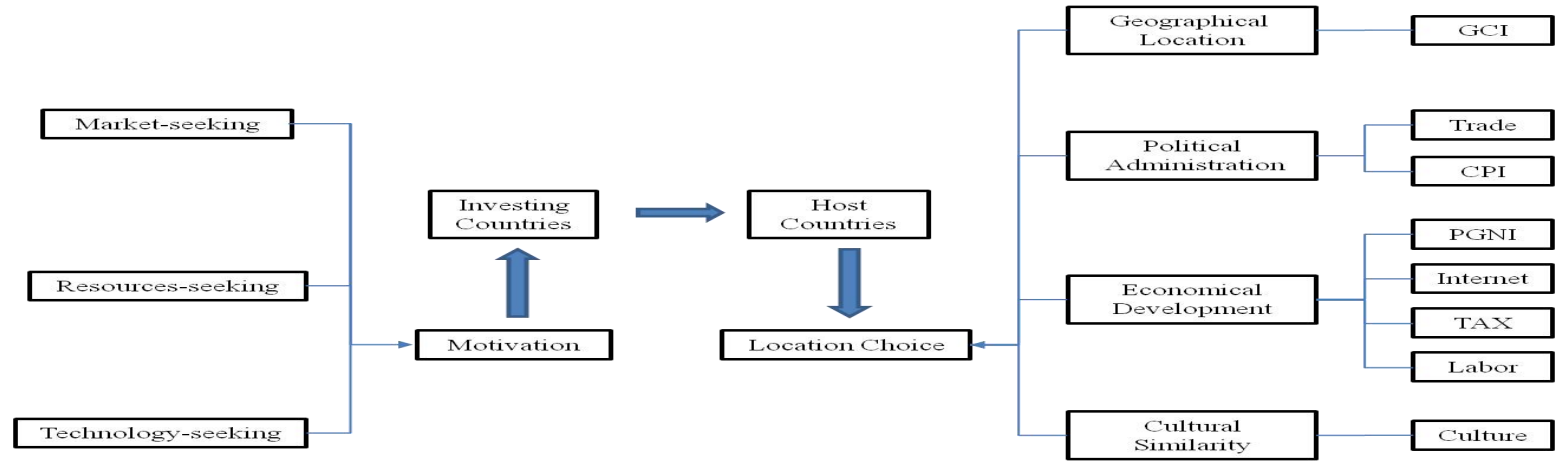

Fig. 1. The logic diagram.

\section{THE VARIABLE SELECTION}

In the light of determinants selection above, this paper has captured the finest details, improved data sources, and perfected analysis paths where accessory branches are attached to build a general analysis framework. This paper selects the top 70 FDI recipient countries over the time span from 2003 to 2014 as data samples, and utilizes STATA software to analyze how the social, political, economic, cultural determinants in different recipient countries directly or indirectly affect the stock of China's OFDI by Panel Data models. By and large, this article selects variable "Trade", on behalf of the total Chinese import and export trade, to reflect the degree of trade tightness between China and the host country; This article selects variable "Labor", representing the index of total labor, to display absorption of host market ;This article selects variable "PGNI" as the sign of the host per capita national income, to reveal the host labor cost; This text selects variable "Internet" to show the index of Internet users, embodying situation of the host infrastructures; This text selects the variable "CPI" to explore the host Political management in the name of Corruption Perceptions Index; The variable "Tax", "GCI", and "Culture" are chosen to measure the host tax rate, global competitiveness and cultural comparability. These numbers are conservative best estimates, based on data from Chinese, U.S. and international agencies, industry associations, and other sources, such as China Statistical Yearbook, World Bank, Global Competitiveness Report, KOF Index of Globalization and Transparency International.

TABLE I. The ORIgin AND REFERENCE Of VARIABLES

\begin{tabular}{|c|c|c|c|}
\hline VARIABLES & INDEXES & DETEMINANTS & DATA SOURCES \\
\hline Trade & $\begin{array}{l}\text { The trade volume between China and the } \\
\text { sample countries }\end{array}$ & $\begin{array}{l}\text { Measuring the degree of closeness of trade relationship } \\
\text { between China and the host countries }\end{array}$ & $\begin{array}{l}\text { China Statistical } \\
\text { Yearbook(2003-2014) }\end{array}$ \\
\hline Labor & The total labor force in sample countries & Measuring the degree of market saturation in host countries & World Bank \\
\hline PGNI & Per-capita Gross National Income & $\begin{array}{l}\text { Measuring the degree of labor burden, not only included the } \\
\text { salary the employee earns ,but also included pension costs, } \\
\text { health insurance, housing provident fund and so on }\end{array}$ & World Bank \\
\hline Internet & $\begin{array}{l}\text { The number of Internet users in sample } \\
\text { countries }\end{array}$ & $\begin{array}{l}\text { Measuring the degree of infrastructure construction in the } \\
\text { host country }\end{array}$ & World Bank \\
\hline CPI & $\begin{array}{l}\text { The score of Corruption Perceptions Index in } \\
\text { sample countries, and the index is in a } 10 \text { - } \\
\text { point scale, "TEN" means the least corrupt } \\
\text { place in the world, "ZERO" means the most } \\
\text { corrupt place }\end{array}$ & $\begin{array}{l}\text { Measuring the degree of political and Security management, } \\
\text { reflecting the additional costs the Chinese enterprises may } \\
\text { encounter, such as bribery, security risks, personal attacks, } \\
\text { etc }\end{array}$ & $\begin{array}{l}\text { Transparency } \\
\text { International }\end{array}$ \\
\hline TAX & The total tax rate of the sample countries & $\begin{array}{l}\text { Measuring the unintended consequence and impact of } \\
\text { different tax burden in host countries when China enterprises } \\
\text { operated business activities }\end{array}$ & World Bank \\
\hline GCI & $\begin{array}{l}\text { The score of Global Competitiveness Index, } \\
\text { which is in a } 10 \text {-point scale, and the higher } \\
\text { the score, the stronger the comprehensive } \\
\text { ability }\end{array}$ & $\begin{array}{l}\text { Measuring the comprehensive picture of host countries } \\
\text { 'competitiveness based on } 12 \text { indexes evaluating system, } \\
\text { such as macroeconomic stability, health and primary } \\
\text { education, higher education and training, commodity market } \\
\text { efficiency, labor market efficiency, financial market } \\
\text { maturity, technology and equipment, market size, business } \\
\text { maturity, innovation, etc }\end{array}$ & $\begin{array}{l}\text { Global } \\
\text { Competitiveness } \\
\text { Report(2004-2014) }\end{array}$ \\
\hline CULTURE & $\begin{array}{l}\text { The score of Cultural similarity index. Points } \\
\text { are assigned from one (lowest globalization) } \\
\text { to one hundred (highest globalization) in } \\
\text { cultural globalization scales based on the } \\
\text { reach of those areas beyond national } \\
\text { boundaries }\end{array}$ & $\begin{array}{l}\text { Measuring the degree of similarity in cultural traditions, } \\
\text { customs, interpersonal skills and other aspects of the society } \\
\text { etiquette }\end{array}$ & $\begin{array}{l}\text { KOF Index of } \\
\text { Globalization }\end{array}$ \\
\hline
\end{tabular}




\section{THE EMPIRICAL ANALYSIS}

The empirical operation process: firstly, Hausman tests are made to determine whether the multi-factor models are formulated in fixed-effect or random-effects models; Secondly, describing the formula of

$$
y_{i t}=\alpha_{i t}+\beta_{i t} \cdot \chi_{i t}+\varepsilon_{i t}, i=1,2 \ldots N ; t=1,2 \ldots T
$$

$\mathrm{Y}$ is assigned to the explained variable "OFDI", and $\mathrm{X}$ is assigned to explanatory variables, containing two or more indexes mentioned in the last paragraph; last but not the least, the significance of is estimated and the empirical results are listed in the form of a table to interpret the practical meaning.

In order to explore how the eight determinants of trade relationships, labor costs, public infrastructures, the social security, the tax burden, cultural practices and other aspects affected the market scale and trade volume of China's overseas investment, six regression formulae are established:

$$
\begin{aligned}
& \text { OFDI }_{i t}=\alpha_{i t}+\operatorname{Trade}_{i t} \cdot \beta_{11}+P G N I_{i t} \cdot \beta_{12}+\text { Labor }_{i t} \cdot \beta_{13}+ \\
& \text { Internet }_{i t} \cdot \beta_{14}+C P I_{i t} \cdot \beta_{15}+\varepsilon_{i t} \\
& \text { OFDI }_{i t}=\alpha_{i t}+\text { Trade }_{i t} \cdot \beta_{21}+\text { PGNI }_{i t} \cdot \beta_{22}+\text { Labor }_{i t} \cdot \beta_{23}+ \\
& \text { Internet }_{i t} \cdot \beta_{24}+\operatorname{TAX}_{i t} \cdot \beta_{25}+\varepsilon_{i t} \\
& \text { OFDI }_{i t}=\alpha_{i t}+\text { Trade }_{i t} \cdot \beta_{31}+P G N I_{i t} \cdot \beta_{32}+\text { Labor }_{i t} \cdot \beta_{33}+ \\
& \text { Internet }_{i t} \cdot \beta_{34}+C P I_{i t} \cdot \beta_{35}+T_{A X} \cdot \beta_{36}+\varepsilon_{i t} \\
& \text { OFDI }_{i t}=\alpha_{i t}+\text { Trade }_{i t} \cdot \beta_{41}+P G N I_{i t} \cdot \beta_{42}+\text { Labor }_{i t} \cdot \beta_{43}+ \\
& \text { Internet }_{i t} \cdot \beta_{44}+G C I_{i t} \cdot \beta_{45}+\varepsilon_{i t} \\
& \text { OFDI }_{i t}=\alpha_{i t}+\text { Trade }_{i t} \cdot \beta_{51}+P G N I_{i t} \cdot \beta_{52}+\text { Labor }_{i t} \cdot \beta_{53}+ \\
& \text { Internet }_{i t} \cdot \beta_{54}+C P I_{i t} \cdot \beta_{55}+T A X_{i t} \cdot \beta_{56}+G C I_{i t} \cdot \beta_{57}+\varepsilon_{i t} \\
& \text { OFDI }_{i t}=\alpha_{i t}+\text { Trade }_{i t} \cdot \beta_{61}+P G N I_{i t} \cdot \beta_{62}+\text { Internet }_{i t} \cdot \beta_{63}+ \\
& C P I_{i t} \cdot \beta_{64}+C U L T U R E_{i t} \cdot \beta_{65}+\varepsilon_{i t}
\end{aligned}
$$

\begin{tabular}{|c|c|c|c|c|c|c|}
\hline \multirow{2}{*}{ variable } & (2) & (3) & (4) & (5) & (6) & (7) \\
\hline & RE & FE & FE & RE & $\mathbf{F E}$ & $\mathrm{RE}$ \\
\hline \multirow[t]{2}{*}{ trade } & $0.0377^{* *+}$ & $0.044^{* * *}$ & $0.0432^{* *+}$ & $0.0417^{*+*}$ & $0.0418^{* * *}$ & $0.0201^{* * *}$ \\
\hline & $(15.60)$ & (7.22) & (6.99) & (14.65) & (6.41) & $(12.42)$ \\
\hline \multirow[t]{2}{*}{ pgni } & $5.4956^{* * *}$ & $16.5341^{* * *}$ & $15.1525^{* * *}$ & $3.8538^{* * *}$ & $15.46002^{* * *}$ & $3.0045^{* * *}$ \\
\hline & $(4.51)$ & (6.99) & (6.38) & $(2.81)$ & (6.05) & (3.48) \\
\hline \multirow[t]{2}{*}{ labor } & -0.0005 & 0.003 & 0.0063 & -0.0004 & 0.0063377 & \\
\hline & $(-1.61)$ & (0.59) & (1.21) & $(-1.12)$ & $(0.75)$ & \\
\hline \multirow[t]{2}{*}{ internet } & $1825.234^{* * *}$ & 913.4536 & $1735.678^{*}$ & $1976.114^{* *}$ & 1404.92 & $1567.323^{* * *}$ \\
\hline & (2.59) & (0.94) & (1.75) & (2.24) & (1.26) & (3.02) \\
\hline \multirow[t]{2}{*}{ cpi } & $-6409.877^{* * *}$ & & $-8196.198^{* * *}$ & & $-10484.37^{* * *}$ & $-2215.348^{* * *}$ \\
\hline & $(-6.15)$ & & $(-3.41)$ & & $(-3.76)$ & $(-2.79)$ \\
\hline \multirow[t]{2}{*}{$\operatorname{tax}$} & & $-2367.652^{*}$ & $-2497.772^{*}$ & & $-2215.378^{*}$ & \\
\hline & & $(-1.68)$ & $(-1.79)$ & & $(-1.42)$ & \\
\hline \multirow[t]{2}{*}{ gci } & & & & $-139846.8^{* \neq *}$ & $108823.3^{* *}$ & \\
\hline & & & & $(-3.94)$ & $(2.15)$ & \\
\hline \multirow[t]{2}{*}{ culture } & & & & & & $-1445.628^{* \neq *}$ \\
\hline & & & & & & $(-3.03)$ \\
\hline within- $\mathbf{R}^{2}$ & 0.4386 & 0.3743 & 0.3891 & 0.4565 & 0.3872 & 0.3836 \\
\hline prob $>$ chi 2 & 0.3604 & o & 0.0822 & 0.2973 & 0.0301 & 0.3735 \\
\hline
\end{tabular}

TABLE II. The Determinants OF OUtward DiRect InVESTMEnt By ChInA, 2003-2014

a. Asterisks $* * *, * *, *$ denote $1 \%, 5 \%$ and $10 \%$ significance levels, respectively.

According to the analysis of the panel data, the index "Trade" was found to have a significant positive effect at the 0.01 level on flows of Chinese OFDI from model one to model six, illustrating that tangible goods trade as a primary consideration controlled the lifeline when Chinese enterprises ran outward foreign investment projects. Frequent trade nations with frequent trades can also be converted to the main receiving investment nations readily, especially in early stages of development.

The index "PGNI" was always showing a positive relationship with China OFDI on the significant level of one percent from all the models above, implying that brilliant prospects in host society development are more likely to attract Chinese investors, especially in emerging economies. b. The value in bracket is t-statistic (fixed effects model) or z-statistic (random effects model)

No statistically significant evidence can be figured out between the index "Labor" and China OFDI from model one to model five, which can be interpreted that variation ranges of China OFDI are very smooth within the limit of free floating regardless of the host country's market size.

The correlation between the index "Internet" and China OFDI varied according to time and different restrictions. Specifically, a positive correlation appeared in the circumstance of government corruption and cultural discrepancy, but infrastructure construction had not significant effect on China OFDI when taking high tax burden into consideration.

The index "CPI" had intensively obvious negative relevance to China OFDI, stating clearly that loopholes in the management of the department and defects in the system of 
administration approval can provide Chinese investors with more convenient access methods and more efficient market prolongations by means of bribery.

The index "TAX" had slightly negative association with China OFDI on the level of 10 percent, clarifying that China enterprises had the stomach for these countries or regions where there is a tax preference.

Prominent connection how the index "GCI" and "CULTURE" affected China OFDI isn't of existence, since that the index "GCI" toke on two opposite effects and the index "GCI" only in model six showed negative linkage, let alone with some limited prerequisites attached. But what we can see is that a low value of "CPI" corresponded to a low value of "CULTURE" and a high value of "GCI".

The empirical results show that China's OFDI tends to sprout in developing countries, rather than in developed countries, it is mainly attributed to the complementary economic models between China and other developing countries, such as the resource-seeking guidance corresponding to rich resources reserves and equipmentengineering outputs corresponding to infrastructures deficiencies, whereas varieties of investment barriers in developed countries are relatively high.

\section{CASES ANALYSES}

The actual situation is that Asia, Latin America and Africa, as main recipient regions accounted for more than $80 \%$ of all the China OFDI stock, where unsound infrastructure construction, defective state governance, low income levels and booming development speed is a normal. To say concretely, the current conditions verify the empirical backing with one accord.

Up to 2014, China OFDI stock in Asia had accumulatively accounted for $68.10 \%$, on the one hand, the contiguous territory boundaries and similar cultural habits have promoted trade exchanges between China and ASEAN since ancient times, on the other hand, the policy of "one belt and one road" and the process of RMB internationalization offer an bursting point to launch a counterattack ranging over high-speed rail projects and other overseas investment, which can deepen economic cooperation with ASEAN and break the divisive effect originating from some conspiracy doctrines.

Latin American has received a \$22billion loan from China in recent years to actively press ahead with the infrastructure development plan, which makes China's OFDI in Latin American have accounted for $12 \%$, involving the research of Science and technology, the system of transportation, and the field of finance. For example, China has funded to build nuclear-power plants in Argentina and launch the first satellite in Bolivia for joint cooperation with high-tech fields. What's more, feasibility study of Bi-ocean Railroad is incorporated into the ChinaBrazil-Peru agenda to break the American monopoly position in the Panama Canal of logistics. Additionally, Industrial and Commercial Bank of China has acquired 80 percent of Standard Bank Argentina and its two affiliates, which can not only extend ICBC's networks, but also can offer better serve for the booming bilateral trade between China and Argentina.

Although the share of China's OFDI stock in Africa is low, only $3.4 \%$, actually, the increasing rate of investment is extremely fast. According to statistics, the cumulative loans from China to Africa has reached $\$ 1$ trillion, mainly spreading in the construction of railways, ports, and natural resources projects. For one thing, Chinese investment projects in Africa are industrial advantage or complementary aspects, out of the perfect match in demand and supply, not opportunism. For another, China has provided outstanding management talents to Africa, for the sake of helping their industrial transformation and upgrading with a long-term economic aid, and moreover, actively organized medical rescue teams to fight the spread of various viruses in a pattern of humanitarian aids. These measures not only can regulate the development pace of bilateral economy, but also win cooperation partners as well as discourse right in the world conference.

\section{CONCLUSIONS}

These experiments suggest how the primary causes of China OFDI coped steadily with an uncertain economy, such as "Trade", "PGNI", "Internet", "CPI". The results also demonstrated how the secondary considerations of China OFDI were in a shaky state with the accompaniment of shifty conditions, such as "TAX", "GCI", "CULTURE", "Labor". Many-to-many interactive influences act on the OFDI life phases of "birth-growth-development-maturity", where there is a synergetic or inhibitory effect. All in all, combining with the actual cases of multinational company carrying out foreign direct investment, some matters should be paid great attention: the government should vigorously support the platform construction in related policies, systems, institutions and other fields, and Chinese enterprises should focus on training corporate social culture, improve global governance, strengthen enterprise network operation and other strategic development plans. Only in this way, can China's layout of "one belt and one road" and the enterprise's reform of "supply side" come true.

\section{ACKNOWLEDGMENT}

This work was derived from the national conditions, guided by the supervisor, and supported by the school and family, to solve the practical problem of China.

\section{REFERENCES}

[1] Y.C. Song, "Result Verification on the Purposes of China's OFDI - A Perspective of Resource-seeking OFDI," Inquiry into Economic Issues, No. 8, 2013, pp. 123-129.

[2] B. Hu, and F.H. Deng, "Corruption Distance and China's OFDI -- the Integration Perspective of Institution-based View and Behavioristics," Finance \& Trade Economics, 2014, pp. 82-92.

[3] Y.Q. Wang, J.L. Du, and K. Wang, "The Determinants of China's OFDI Location Choice: System, Tax and Resource Endowment," Economic Research, 2014, pp. 126-142. 
[4] L. Li, and Z.Y. Zheng, "Debate Whether the Type of China's OFDI is Resource-seeking," Journal of International Trade, 2012, pp. 146-157.

[5] S.K. Liu, "The Influence of Host Country's Infrastructure on China's OFDI --Based on Transnational Panel Data," Modern Business Trade Industry, 2016, pp. 44-45.

[6] X.M. Yang, and C. Zhang, "Factor Endowments, Policy Tilt, and China's OFDI -- Based on the Provincial Panel Data Analysis," Journal of International Trade, 2014, pp. 124-134.

[7] Y. Wang, H. Gao, and S.H. Hong, "Exploration and Analysis of China's OFDI structure," Tax and Economy, 2014, pp. 43-47.
[8] C.F. He, Q. Guo, and P.S. Zou, "Research of China's OFDI Location Choice Based on the perspective of relationship," World Geographical Research, 2013, pp. 1-12.

[9] Z. Pan, and Z.K. Jin, "Bilateral Political Relations, Host Country's Systematic Risks and China's OFDI," Finance \& Trade Economics, 2015, pp. 85-97.

[10] H.L. Xu, and L.H. Li, "The Impact of cultural differences on China's OFDI," Statistics and Decision-Making, 2011, pp. 154-156. 